\title{
Power Grid Project Cost Intelligent Evaluation Technology Based on Probability Statistics
}

\author{
Yan $\mathrm{Lu}^{1, *}$, Chenhao $\mathrm{Niu}^{2}, \mathrm{Xiaomin} \mathrm{Xu}^{1}$ and Mian Xing ${ }^{3}$ \\ ${ }^{I}$ School of Economics and Management, North China Electric Power University, Beijing, 102206, China; ${ }^{2}$ Information \\ Management Office, North China Electric Power University, Beijing, 102206, China; ${ }^{3}$ Mathematics and Physics De- \\ partment, North China Electric Power University, Beijing, 102206, China
}

\begin{abstract}
Power grid projects are related to national economy and people's livelihood. It is particularly important to control the cost. And when controlling the cost, it is a key link to evaluate the cost. In the actual cost evaluation of the past, it is commonly used to compare the settlement amount with the approved budget amount. However, this method is more general. And it has strong subjectivity. In this paper, the probability analysis and the power grid project evaluation are combined. Based on the past similar projects cost library, realize the standardization, rationalization and objective of the cost evaluation. Finally, take a substation and a line project for actual evaluation. The results show that this technology can realize the intelligent evaluation of power grid projects, which can be further promoted and applied.
\end{abstract}

Keywords: Cost, intelligent evaluation, power grid project, probability statistics.

\section{INTRODUCTION}

In the construction of engineering projects, the project cost is always the most pressing question of the investors and the project owners. Power grid projects are related to national economy and people's livelihood. It is particularly important to control the cost. The control of engineering projects cost is to control the cost within the approved budget range in the investment decision-making phases, the construction drawing design phase and the construction implementation stage. The projects can get good investment benefits and social benefits by correcting the deviation. Among, the cost evaluation is the key link to ensure the cost control [1]. In the actual cost evaluation of the past, it is commonly used to compare the settlement amount with the approved budget amount in the phase of project completion final accounts. If the settlement amount not beyond the budget amount, the project estimate accuracy is high. Otherwise, the implementation of cost control is not reasonable. However, this evaluation method is more general. In actual, maybe some child cost are over budget. There may be the situation that some child costs offset with each other. Thus this method is not conducive to the analysis of the engineering cost. And it is not conducive to the control of engineering cost. The costs need to be further elaborated.

At present, there are few study on the projects' cost evaluation at home and abroad. Literature [2] introduced the advanced digital management idea into the project cost evaluation. It formed a series of practical and effective methods based on the synthesis of design indexes and the analysis of the history of engineering data. Literature $[2,3]$ mainly evaluated the risk of the project cost in order to achieve cost effective evaluation using the method of probability analysis. Literature [4-5] established a mathematical model for project evaluation using the extreme statistical thought, fully considering the influence of psychological factors. And examples proved that the operation was simple, easy to promote. Literature [6] built the evaluation and analysis model using the sensitivity analysis method based on neural network, so as to realize the fast evaluation of the power line project cost.

In this paper, the cost evaluation of power grid project is the specific object. The probability statistics method and the power grid projects are combined to further study and application in order to achieve the ultimate goal of the standardization and rationalization of cost evaluation. Finally, form a feasible evaluation method, which can improve the efficiency of handle affairs personnel, and assist managers in decision analysis.

\section{POWER GRID PROJECT COST RISK FACTORS ANALYSIS}

\subsection{Power Grid Project Cost Reconstruction}

Substation and line project are the typical power grid projects. Generally, the cost of substation project includes project construction fee, project installation fee, equipment procurement Fee, and other fee. The cost of line project includes project installation fee, auxiliary facilities project fee and other fee. The cost of cable line project includes equipment procurement fee, project construction fee, project installation fee, auxiliary facilities project fee and other fee.

Reconstruct the risk factors of power grid project according to the construction of cost. The results are as following. The cost of substation project includes project construction 
Table 1. The analysis and statistics of $220 \mathrm{kV}$ outdoor new substation project.

\begin{tabular}{|c|c|c|c|c|}
\hline No & The Child Fee & $\begin{array}{c}\text { The Contribution Rates of } \\
\text { Estimate Cost/\% }\end{array}$ & $\begin{array}{c}\text { The Contribution Rates of } \\
\text { Final Cost /\% }\end{array}$ & $\begin{array}{c}\text { The Probability of Beyond } \\
\text { the Estimate Cost } \mathbf{\%}\end{array}$ \\
\hline \hline 1 & project construction fee & 19.60 & 21.02 & 30.61 \\
\hline 2 & equipment procurement Fee & 48.60 & 47.89 & 31.63 \\
\hline 3 & project installation fee & 9.26 & 10.62 & 24.49 \\
\hline 4 & other fee & 10.45 & 10.82 & 30.61 \\
\hline 5 & construction site requisition and compensa- & 8.92 & 9.41 & 14.29 \\
\hline 6 & tion fee & 0.52 & 0.51 & 0.00 \\
\hline 7 & production preparation fee & 2.47 & 100 & \\
\hline
\end{tabular}

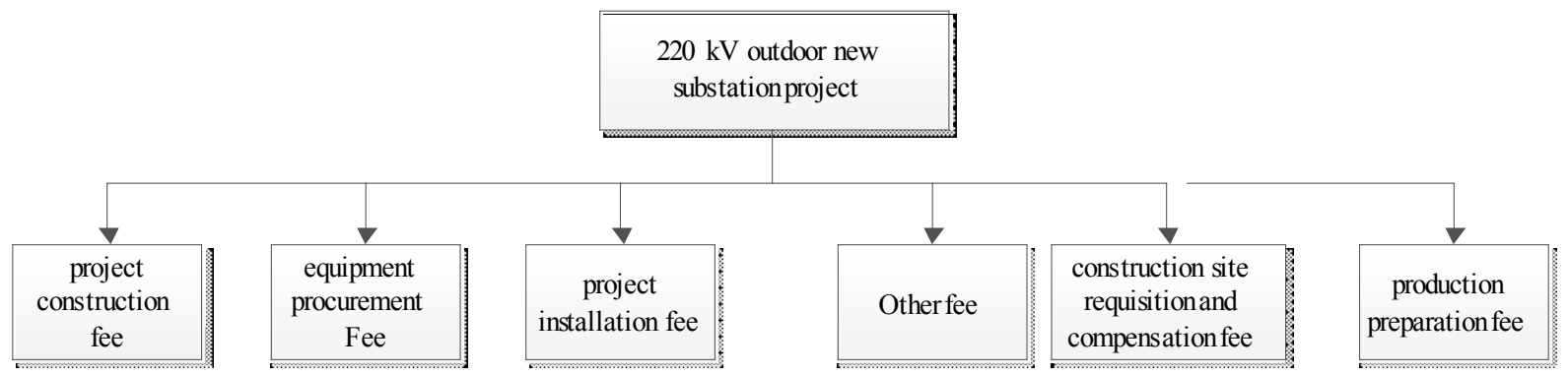

Fig. (1). The intelligent evaluation risk index system of $220 \mathrm{kV}$ outdoor new substation project.

fee, project installation fee, equipment procurement fee, construction site requisition and compensation fee, early stage of project work fee, environmental monitoring test fee, soil and water conservation project acceptance and compensation fee, pile foundation detect fee, big transportation measures fee, design fee, investigate fee, supervision fee, production preparation fee, basic preparation fee and other fee.

The cost of line project includes ontology fee, auxiliary facilities project fee, prepare the years spreads, construction site requisition and compensation fee, early stage of project work fee, environmental monitoring test fee, soil and water conservation project acceptance and compensation fee, pile foundation detect fee, auxiliary construction fee, road construction fee, production preparation fee, basic preparation fee and other fee.

\subsection{Power Grid Project Cost Intelligent Evaluation Risk Index System}

As for the substation project and the line project, the construction cost level is different with the different technical conditions. For the substation project, the technical conditions, such as, the voltage grade, construction type (new or expansion), substation type, presence of regulating, will have great influence on cost level [7]. For the line project, the cost level is related to these factors, such as, the voltage grade, budget rules version, line length, line type, ice thickness [8]. Different project types, different cost construction. Corresponding, different evaluation risk index system. So build the evaluation risk index system based on the construction type. This paper build the evaluation risk index system for the typical engineering category.

\subsubsection{Substation Project Cost Intelligent Evaluation Risk Index System}

This paper takes the $220 \mathrm{kV}$ outdoor new substation project as an example to build a typical substation project cost intelligent evaluation risk index system. Base on the analysis on the cost data of $220 \mathrm{kV}$ outdoor new substation projects of a province in China, we can get the contribution rates of child fees, the probability of beyond the estimate cost. The results are as shown in Table $\mathbf{1 .}$

Form Table 1, we can see that, every child fee has different influences on $220 \mathrm{kV}$ outdoor new substation project. Among them, not only the contribution rate of basic preparation fee is the lowest, but the probability of beyond the estimate cost is the lowest as well. The probability is almost to zero. So we can make sure that the basic preparation fee is not the main factor of substation construction cost risk. It can be removed. At the same time, the other six factors can be identified as the main factors of cost risk index system. Compare the estimate accounts with the final accounts. It can reflect the risk of beyond the estimate cost. The intelligent evaluation risk index system of $220 \mathrm{kV}$ outdoor new substation project is as shown in Fig. (1).

\subsubsection{Line Project Cost Intelligent Evaluation Risk Index System}

This paper takes the $110 \mathrm{kV}$ long distance overhead line project as an example to build a typical line project cost in- 
Table 2. The Analysis and statistics of $110 \mathrm{kV}$ long distance overhead line project.

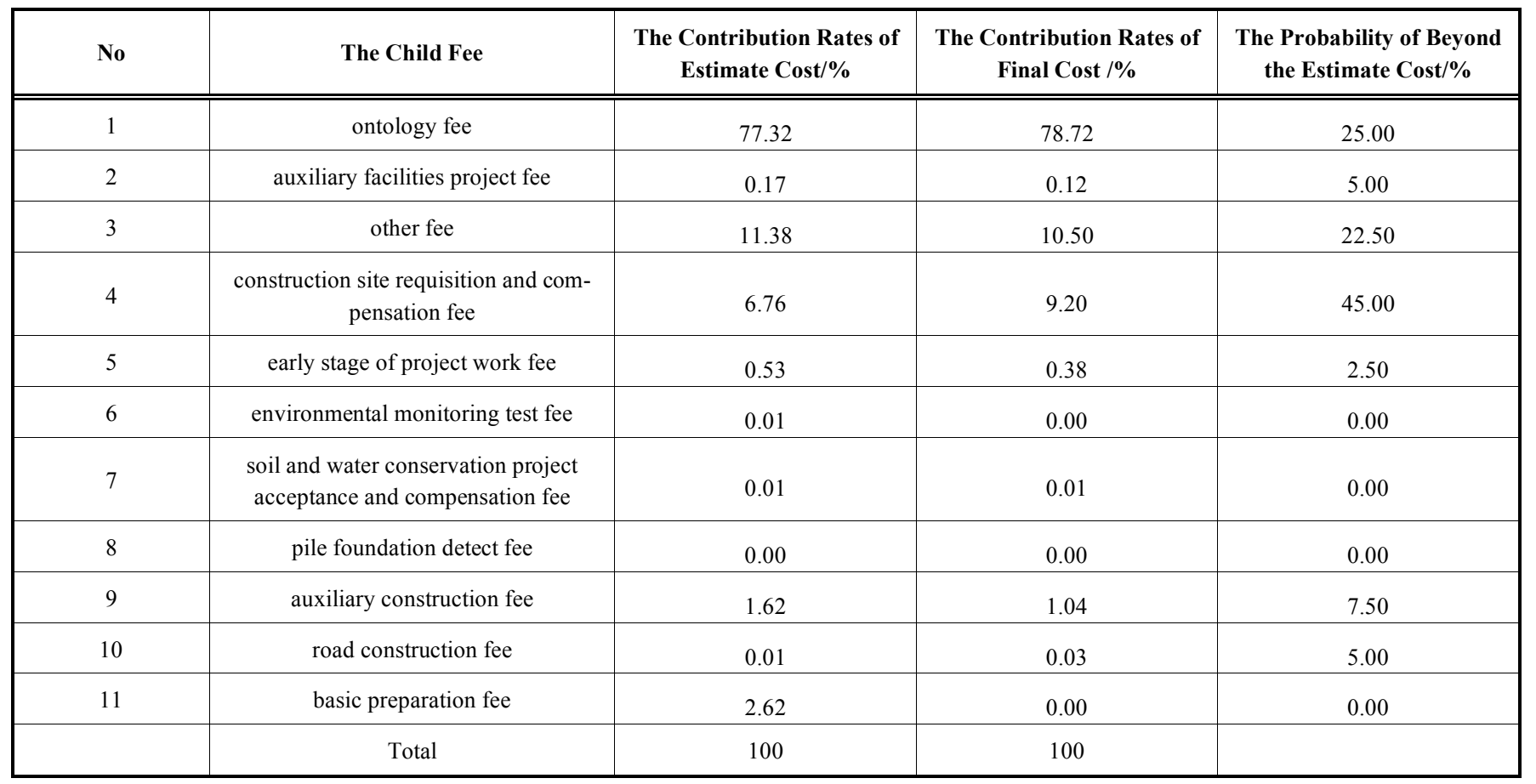

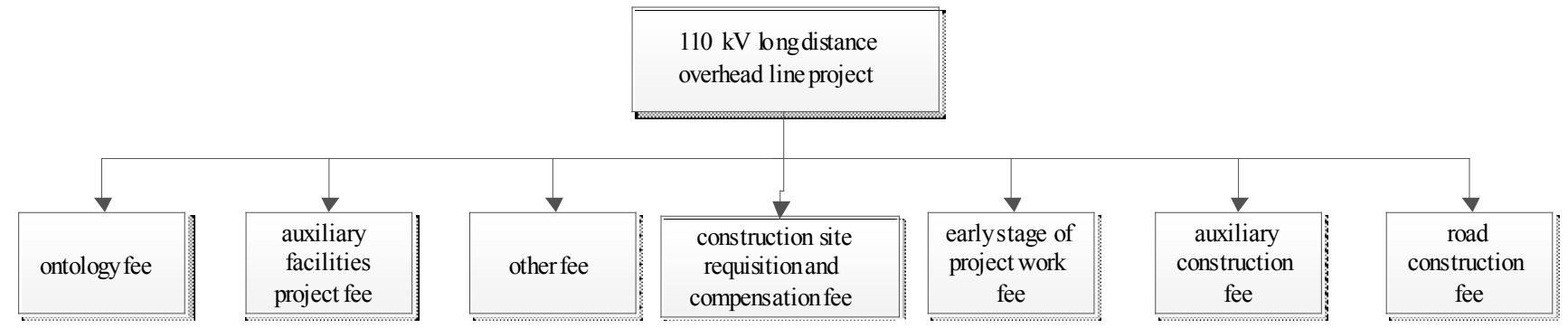

Fig. (2). The intelligent evaluation risk index system of $110 \mathrm{kV}$ long distance overhead line project.

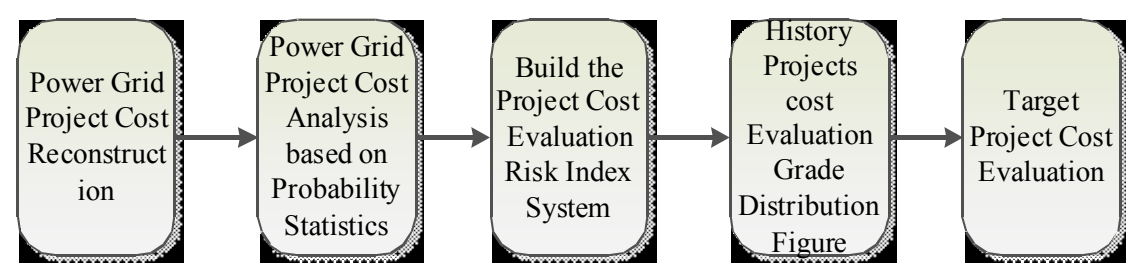

Fig. (3). The technology route of power grid project cost evaluation.

telligent evaluation risk index system. Base on the analysis on the cost data of $110 \mathrm{kV}$ long distance overhead line projects of a province in China, we can get the contribution rates of child fees, the probability of beyond the estimate cost. The results are as shown in Table 2.

Form Table 2, we can see that, every child fee has different influences on $110 \mathrm{kV}$ long distance overhead line project. Among them, not only the contribution rates of environmental monitoring test fee, soil and water conservation project acceptance and compensation fee, pile foundation detect fee and basic preparation fee are the lowest, but the probability rates of beyond the estimate cost are the lowest as well. The probability rates are almost to zero. So we can make sure that the four child fees are not the main factors of sub- station construction cost risk. They can be removed. At the same time, the other seven factors can be identified as the main factors of cost risk index system. Compare the estimate accounts with the final accounts. It can reflect the risk of beyond the estimate cost. The intelligent evaluation risk index system of $110 \mathrm{kV}$ long distance overhead line project is as shown in Fig. (2).

\section{POWER GIRD PROJECT COST EVALUATION TECHNOLOGY}

\subsection{Power Grid Project Cost Evaluation Technology} Route

The technology route of power grid project cost evaluation is shown in Fig. (3). 


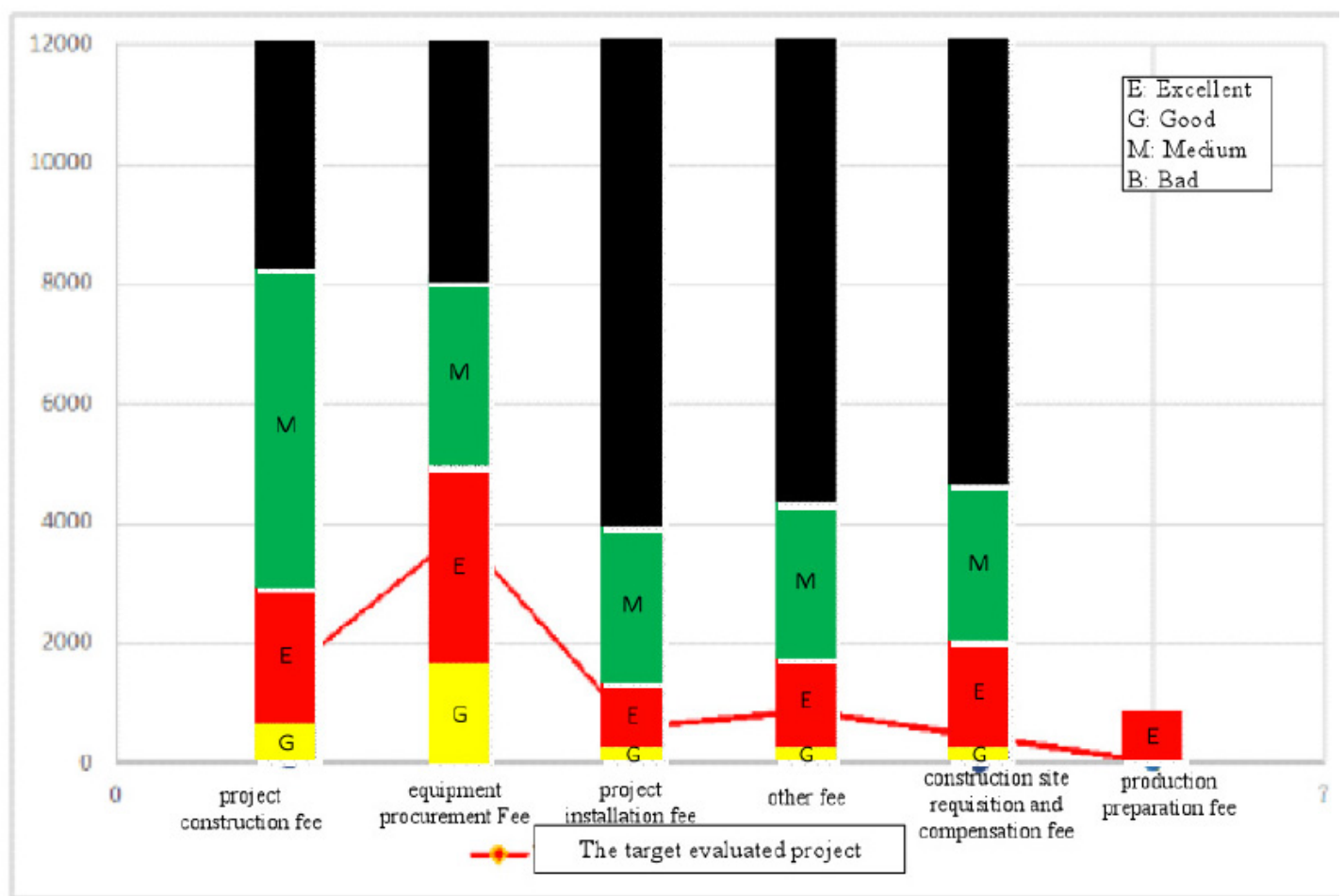

Fig. (4). The cost evaluation grade distribution figure of $220 \mathrm{kV}$ outdoor new substation project.

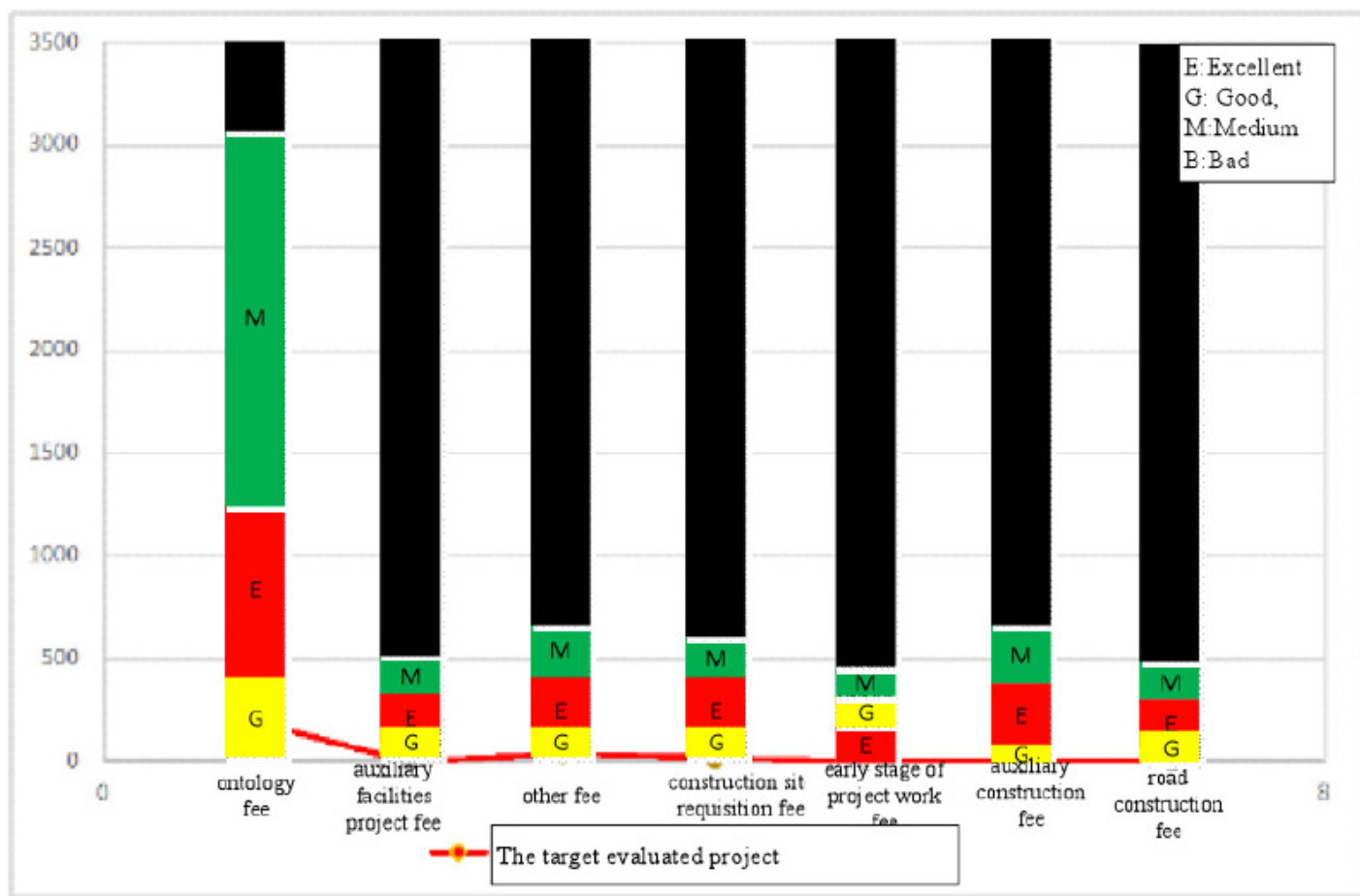

Fig. (5). The cost evaluation grade distribution figure of $110 \mathrm{kV}$ long distance overhead line project.

\subsection{The Empirical Research of a Substation Project}

This paper takes a $220 \mathrm{kV}$ outdoor new substation project which has been completed in 2012 as an example to evaluate the rationality of the cost. Firstly, select $97220 \mathrm{kV}$ outdoor new substation history projects based on the cost analysis data between the Year 2006 to 2012. Then, draw the cost evaluation grade distribution figure according to the corresponding historical data. As shown in Fig. (4).
Firstly, we can see the level and the distribution of risk costs of history projects from the grade distribution figure. The cost evaluation of the target project is the rating of risk cost. Thus, each child risk cost can be divided into various levels (excellent, good, medium and bad). Finally, mark the parameter values on the grade distribution figure. We can easily determine the evaluation result of target engineering cost. From Fig. (4), we can get that the evaluation result of 
target engineering project is "excellent". Besides, each evaluation level of risk costs is "excellent".

\subsection{The Empirical Research of a Line Project}

This paper takes a $110 \mathrm{kV}$ line project which has been completed in 2012 as an example to evaluate the rationality of the cost. Firstly, select $39110 \mathrm{kV}$ long distance overhead line project based on the cost analysis data between the Year 2006 to 2012. Then, draw the cost evaluation grade distribution figure according to the corresponding historical data. As shown in Fig. (5).

In the same way, we can see the level and the distribution of risk costs of history projects from the grade distribution figure. From Fig. (5), we can get that the evaluation result of the target engineering project is "good". For the child cost, the evaluation result of early stage of project work fee is "excellent". The results of other child costs are all "good".

\section{CONCLUSION}

Firstly, this paper combs the cost of power grid project and reconstructed the cost structure. Then, the risk factors of power grid project cost are analyzed based on the probability statistics method. And the intelligent evaluation risk index systems of $220 \mathrm{kV}$ outdoor new substation projects and 110 $\mathrm{kV}$ long distance overhead line projects are established separately. According to the scatter distribution of risk parameter values of the history projects which are the same type as the target project, the levels of child fees and comprehensive cost are divided. The divided levels can be embodied in the figure of cost evaluation grade distribution. Finally, we can evaluate the target project. We can get not only the result of comprehensive cost, but every child risk fee as well.

\section{CONFLICT OF INTEREST}

The authors confirm that this article content has no conflict of interest.

\section{ACKNOWLEDGEMENTS}

This work was partially supported by the Natural Science Foundation of China (71471059), the Project of State Grid Corporation Headquarters and the "Industry-AcademicsResearch" Scientific Project of "Industry-AcademicsResearch" Co-culture Post-Graduate Base in Beijing.

\section{REFERENCES}

[1] R. X. Li, "The implementation phase of project cost dynamic management of construction projects", Xihua University, 2010.

[2] T. Yin, "Research on the method about project budgetary estimation and examination", Chonqing University, 2006.

[3] M. B. Wang, Y. C. Huang, J. Zhang, and P. Y. Geng, "Cost risk evaluating model of power transmission project based on probability analysis method", Power System Technology, vol. 35, no. 2, pp. 26-31, 2011.

[4] B. lv, H. M. Du, and Q. H. Chen, "Study on the risk assessment method based on the probability distribution", Journal of the Academy of Equipment Command \& Technology, vol. 17, no. 4, pp. 5-9, 2006.

[5] F. G. Wang, B. Zeng, J. Yang, D. B. Han, "Project appraisal model based on set-valued statistics and its application", SCI-Technology and Management, no. 3, pp. 47-49, 2006.

[6] Y. Wang, "Research of data mining teehnology used in management of engineering cost for power construction", Chongqing University, 2008.

[7] J. X. Kang, L. S. Ai, and X. R. Zhang, "Analysis of substation project cost influence factors", Journal of Northeast Dianli University, vol. 31, no. 5, pp. 131-136, 2012.

[8] Z. Y. Zhao, Q. L. Lv, W. Y. You, Y. Gao, "An evaluation index model of construction cost for $35 \mathrm{kv}$ transmission lines in rural power network", Power System Technology, vol. 32, no. 14, pp. 96$100,2008$.

Received: September 16, 2014

Revised: December 23, 2014

Accepted: December 31, 2014

(C) Lu et al.; Licensee Bentham Open.

This is an open access article licensed under the terms of the (https://creativecommons.org/licenses/by/4.0/legalcode), which permits unrestricted, noncommercial use, distribution and reproduction in any medium, provided the work is properly cited. 